\title{
THE
}

\section{Content Validation of a Home Parenteral Nutrition-Patient-Reported Outcome Questionnaire}

Tracy-Lee Miller

Geoffrey Greene

University of Rhode Island, ggreene@uri.edu

Ingrid E. Lofgren

University of Rhode Island, ingrid_lofgren@uri.edu

Mary L. Greaney

University of Rhode Island, mgreaney@uri.edu

Marion F. Winkler

Follow this and additional works at: https://digitalcommons.uri.edu/kinesiology_facpubs

The University of Rhode Island Faculty have made this article openly available.

Please let us know how Open Access to this research benefits you.

This is a pre-publication author manuscript of the final, published article.

Terms of Use

This article is made available under the terms and conditions applicable towards Open Access

Policy Articles, as set forth in our Terms of Use.

\section{Citation/Publisher Attribution}

Miller, T.-L., Greene, G.W., Lofgren, I., Greaney, M.L. and Winkler, M.F. (2017), Content Validation of a Home Parenteral Nutrition-Patient-Reported Outcome Questionnaire. Home Nutrition Support, 32: 806-813. doi:10.1177/0884533617725041 Available at: https://doi.org/10.1177/0884533617725041 
Content Validation of a Home Parenteral Nutrition Patient Reported Outcome Questionnaire

\begin{abstract}
Background: Patient reported outcome (PRO) instruments collect information from patients about health conditions and disease management including quality of life (QOL). Clinicians acknowledge patient concerns about QOL but need guidance to assess the nature and severity of individually experienced problems. The Home Parenteral Nutrition (HPN) Patient Reported Outcome Questionnaire (HPN-PROQ) was developed for use during medical appointments or homecare visits to address this gap. The purpose of this research was to provide evidence that the HPN-PROQ items and scale possess content validity.
\end{abstract}

Methods: A mixed method study design was used. In phase 1, cognitive interviews (CI) were conducted with 32 HPN patients. Thematic analysis was used to assess participant understanding of the instructions, items, and response scales and overall utility of the HPNPROQ. In phase 2, 13 expert clinicians evaluated the relevance of items to the HPN population using the Content Validity Index (CVI) to produce item-level (I-CVI) and scale-level (S-CVI) scores. Items with an I-CVI score $\geq 0.783$ were retained.

Results: Fifty-four percent of items were deemed as being comprehensible, acceptable, and clear; $25 \%$ were revised, and $11 \%$ were deleted. In phase $2,79 \%$ of items were rated highly relevant. The S-CVI score was 0.96. The final HPN-PROQ contains 34 items.

Conclusion: This study established acceptable content validity of the HPN-PROQ. This PRO questionnaire may help foster patient-clinician communication about lifestyle adaptation and QOL. 
Content Validation of a Home Parenteral Nutrition Patient Reported Outcome Questionnaire

\section{Background}

Home parenteral nutrition (HPN) is a complex therapy involving the intravenous infusion of nutrients and fluids to individuals who have intestinal failure or dysfunction. Home-based care, with support from family members and trained healthcare professionals, provides patients the opportunity to receive nutritional support in a familiar and comfortable environment outside of a hospital or institutional setting. There are, however, known factors that negatively affect the quality of life (QOL) of HPN patients including decreased physical, psychological and social function along with increased occurrences of depression, drug dependency, sleep disturbance, frequent urination, fear of therapy related complications, inability to eat, and financial distress. ${ }^{1-7}$ Furthermore, the emotional and physical complications associated with HPN and underlying disease require extensive lifestyle adaptation for patients and their families. ${ }^{4,8,9}$

At present, there is one validated therapy-specific instrument $\left(\mathrm{HPN}-\mathrm{QOL}^{\odot}\right)^{10}$ to support the HPN population, however, data from the Sustain Registry indicated less than $2 \%$ of enrolled HPN patients reported having QOL measured. ${ }^{11}$ Three research reports have been published using the $\mathrm{HPN}-\mathrm{QOL}^{\odot}$ to assess changes among HPN patients with short bowel syndrome receiving teduglutide ${ }^{12,13}$ and among patients undergoing intestinal transplantation..$^{14}$ A recently developed shorter self assessment version highly correlated with the $\mathrm{HPN}-\mathrm{QOL}^{\odot}$ but not with patients' physical symptoms during HPN. ${ }^{15}$ Quality of life assessment should become part of routine clinical management of HPN patients, but no specific time frame or frequency of conducting an evaluation has been suggested. ${ }^{5,10,12,13}$ To the authors' knowledge, there have been no published reports using the $\mathrm{HPN}-\mathrm{QOL}^{\odot}$ to facilitate communication between healthcare providers and patients. 
Previous research revealed that HPN patients perceive their routine medical appointments as a parenteral nutrition "tune-up" with sessions focusing primarily on medical or disease aspects of care, although they would prefer a more holistic approach with emotional support in addition to medical examination and nutritional assessment. ${ }^{16}$ One such tool to help in this regard is a patient reported outcome (PRO) questionnaire. PRO questionnaires can be used to collect information about a patient's health condition and management including QOL, satisfaction, and adherence to medical regimens. ${ }^{17,18}$ PROs may also be used to screen for functional problems, assess and improve quality of health care, and improve patient-clinician communication while expanding the role of shared or informed decision-making. ${ }^{19}$ When PRO instruments are used in clinical practice, feedback is provided to the clinician with the goal of helping to manage patient care. Such instruments can be invaluable in facilitating patient-clinician communication around QOL and can improve the interactions between patients and their clinicians. ${ }^{17}$

Because there is no known PRO instrument being used in clinical practice, we developed the Home Parenteral Nutrition-Patient Reported Outcome Questionnaire (HPN-PROQ) for patients to self-assess factors that influence QOL or adaptation to HPN. The HPN-PROQ was developed after a series of research activities including comprehensive literature review, expert clinician feedback, and an exploration of the lived experiences of HPN dependent adults. 1,16,20,21 This work established a definition for QOL ("doing what I want to do when I want to do it") and identified factors influencing QOL; eating and mealtime participation, gastrointestinal symptoms, energy level, and ability to do activities of daily living, sleep, psychosocial function and coping, technology burden and training for HPN. ${ }^{16,20}$ The HPN-PROQ in its initial form included 54 items with a 4-point Likert response scale.

A crucial step in the development of questionnaires is to provide evidence that the items and scales possess content validity. ${ }^{22}$ When testing a new instrument there are two primary 
components of importance. ${ }^{23-25}$ First, what is the intent of the question and what do respondents believe the question is asking? Second, what do specific terms, words, and phrases mean, and is that meaning consistent with the question's intent? As PRO instruments assess concepts most relevant and important to a patient, content validity must be established to determine the extent to which an instrument assesses the concepts it proposes to assess. ${ }^{25}$ The primary aim of this study was to determine the content validity of the HPN-PROQ through cognitive interviewing (CI) with HPN patients and computation of the Content Validity Index (CVI) with expert HPN clinicians.

\section{Methods}

A mixed method design using qualitative data (CI) and quantitative methods (CVI) was employed in this study. ${ }^{23-30}$ The purpose was to modify an initial draft of the HPN-PROQ based on CI with HPN patients and thematic analysis (phase 1), followed by establishment of item and scale relevance by expert HPN clinicians using the CVI (phase 2) to produce a final content valid questionnaire. The study protocol was reviewed and approved by the University of Rhode Island Institutional Review Board.

\section{Participants}

For phase 1, participants were recruited from the Oley Foundation [a national, independent, non-profit 501(c)(3) organization for home enteral and parenteral nutrition] via email blast and a call for volunteers in their newsletter as done in other similar studies. ${ }^{20,31}$ Eligibility requirements included being $\geq 18$ years of age, receiving HPN, English-speaking, living in the US, and having the ability to access a computer while simultaneously being on the telephone. Individuals participating in phase 1 interviews completed a brief demographic survey that assessed age, sex, race, highest level of education, medical diagnosis, length of HPNdependency, number of parenteral nutrition infusions per week and infusion hours per day. 
Descriptive statistical analysis was conducted using Microsoft Office Excel (2017) and results are reported as frequency, mean \pm standard deviation, and range.

For phase 2, 33 expert HPN clinicians, stratified by discipline/profession, were invited to participate. Experts were identified through publications on the topic of HPN, leadership in the American Society for Parenteral and Enteral Nutrition home care section, and membership in the Oley Foundation. The goal was to recruit 12 expert physicians, registered dietitians, pharmacists, registered nurses, and home care advocates, as this is an acceptable sample size for completion of the CVI and is comparable to other studies..$^{29,30,32,33}$

\section{Phase 1 - Cognitive Interviews}

One researcher conducted all interviews by telephone at a time convenient for the participant using a semi-structured interview guide with probes. ${ }^{26,27}$ The interviewer read each statement (PRO item) aloud and participants were asked to explain what the statement meant and to repeat the statement in their own words. The interviewer focused on the interpretation of words and phrases rather than considering how the participant would answer the actual question. All interviews were audio-recorded and transcribed verbatim with all identifiers removed. Transcripts were organized on an item-by-item basis. A cross-interview data matrix table was developed to aggregate narratives pertaining to each PRO item and to identify similar patterns and interpretations. An iterative process was used to analyze the data according to the methods described in similar research. ${ }^{20,31}$ Thematic analysis was used to sort and condense findings into themes, support decisions for revision of the HPN-PROQ, and identify problematic items. ${ }^{34}$ Data are presented as representative quotations to illuminate each theme.

Interviews were conducted in two rounds; round 1 tested the instructions, items, and response scale of the draft HPN-PROQ, and round 2 tested subsequent revisions made to the questionnaire. Member checking, a technique used to validate data collected in interviews by 
checking summaries or key points participants made before subsequent rounds of interviews or study termination, was used. ${ }^{35-37}$

\section{Phase 2 - Content Validity Index}

Thirteen expert clinicians participated in an initial round of evaluation by completing a CVI worksheet. A reduced panel of experts $(n=4)$ participated in a second round of evaluations. The item-level (I-CVI) score was calculated by having the expert clinicians rate the relevance of each item on the HPN-PROQ, where 1=not relevant, 2=somewhat relevant, 3=quite relevant, and 4=highly relevant. The I-CVI is defined as the number of expert clinicians selecting a rating of "3" or "4" on each item, divided by the total number of expert clinicians and expresses the proportion of agreement by all experts on the relevancy of each item, as a number between 0 and $1 .^{30}$ To account for chance agreement, a kappa (K) statistic was calculated for I-CVI scores. ${ }^{28}$ An item with high relevance achieved a $\mathrm{K} \geq 0.783 .{ }^{38}$ Items $<0.783$ were removed from the questionnaire. The average of the I-CVI scores was used to designate the scale-level (S-CVI) score; $\mathrm{K} \geq 0.83$ was deemed acceptable. ${ }^{29}$

\section{Results}

\section{Phase 1 - Cognitive Interviews}

A total of 55 adult HPN patients responded to the recruitment announcement, $78 \%$ completed eligibility screening, and $69 \%$ were eligible to participate. The final sample included 32 participants, as interviews were stopped at this point due to data saturation. Twenty participants were interviewed in round 1 and 12 in round 2. The mean length of interviews was $51 \pm 9$ minutes for round 1 , and $37 \pm 10$ minutes for round 2. Demographic characteristics of the HPN patients are shown in Table 1 . Nearly all the participants were Caucasian $(n=31)$ and the majority was female $(n=23)$. The most common medical diagnosis associated with the need for HPN was short bowel syndrome $(n=22)$. Nearly all participants infused parenteral nutrition daily. 
Three themes emerged with respect to the understanding of instructions, items, and response scale: (1) concerns with tone, (2) issues with ambiguity and meaning, and (3) concerns with use of jargon or word choice. With respect to tone, participants voiced concern about the phrases "normal lifestyle", "controls my life", and "limits my freedom" and suggested that questions using these words would be difficult to answer because the definitions were subject to interpretation. These phrases elicited unfavorable comments indicating the tone of the item was overly negative. Participants inconsistently interpreted some items due to ambiguity and unclear meaning. For example, several participants requested clarification around the meaning of the phrase "many times" and quantified "many times" very differently. Clarification was also needed for words such as "satisfied" or "coping". With respect to jargon or word choice, participants recommended more commonly used words for medical terms, such as "ostomy bag" for "ostomy appliance" and "central line" for "catheter".

Participants viewed the HPN-PROQ as being useful and described the items as "beneficial", "human", and "empathetic". They were, however, unsure if clinicians would take the time to address all of their concerns. A few representative quotations are shown below:

- 'I think these questions are phenomenal. I think they nail it...doctors don't ask that (these questions) ...but this feels so human and full of empathy, I really appreciate this kind of questions."

- "A lot of times the patients want to talk about how they feel, but the physicians don't."

- "They know the medical "ins and outs" in terms of intestine and bowels, but they are clueless to what the TPN patient goes through emotionally and physically."

- 'I think it's excellent, it gives somebody topics to focus on when you're at the doctor and you have many questions to ask and then you go home and you remember that you forgot to ask some question... so I think it's a great conversation starter." 
Participants strongly agreed with the QOL definition and repeated the phrase verbatim when asked to restate it in their own words. For example, one participant stated, "I think it's very clear ... it pretty much sums it up. I like that statement"; while another agreed by saying, "I think good quality of life means being able to do what I want to do".

Participants found the 4-point Likert scale difficult to interpret the middle response options. In the initial draft of the HPN-PROQ, for the first 36 items, respondents were asked, "during the past two weeks, how often have you experienced any of the following situations?" The response options were "not at all", "two to three days per week", "more than half of days", or "nearly every day". For items 37-54, respondents were asked "how true or false is each of the following statements for you?" The response options were "definitely false", "mostly false", "mostly true", and "definitely true". Participants described the response option of "two to three days per week" as "three to four days per week", "maybe six times", "I would say four days per week", "more than seven days", and "anywhere between eight to 13 days". Similar concerns were expressed for "mostly true" and "mostly false". These inconsistencies demonstrated that revision to the response scale was necessary. A visual analog scale (VAS) with the stems "not at all" and "every day" and "definitely false" and "definitely true" replaced the 4-point Likert scale in the revised HPN-PROQ. Via member checking, all participants $(n=20)$ provided feedback on the VAS and the majority $(n=16)$ agreed with the revisions and preferred the VAS scale to the 4point Likert scale. They described the VAS as "better", "less time consuming", "a great visual", and "more accurate".

Fifty-four percent of items in the initial draft of the HPN-PROQ were deemed as being comprehensible, acceptable, and clear as they were interpreted as intended. Twenty-five percent of the items were revised and $11 \%$ deleted. In addition to the changes driven by the iterative process, structural revisions were made to the questionnaire including rewording of instructions 
and moving some items to the true/false section. For example, "I feel supported by my family and friends", "I eat and enjoy the foods I want to eat", and "I am confident with my ability to perform TPN procedures on my own" were more easily answered as "definitely true" or "definitely false" rather than "every day" or "not at all".

\section{Phase 2 - Content Validity Index}

In phase 2, 13 expert HPN clinicians including 2 physicians, 3 pharmacists, 3 registered dietitians, 2 registered nurses, and 3 home care advocates participated in evaluating the revised HPN-PROQ with the CVI technique. A reduced panel of 4 expert clinicians (1 physician, 1 registered dietitian, 1 pharmacist, and 1 home care advocate) completed a second round assessment. Individual, adjusted, multi-rater K scores were examined for each of the PRO items as shown in Table 2. There were 34 items scoring "excellent" with I-CVI score $\geq 0.783$; nine items with low relevance were deleted based on I-CVI score $<0.783$. The average of all I-CVI scores produced an S-CVI score of 0.96.

\section{Discussion}

PRO questionnaires increase awareness of health related quality of life by both patients and clinicians and facilitate discussion of treatment goals and expectations. ${ }^{19}$ Many factors influence the QOL of HPN patients, and clinicians need to have the tools necessary to provide both medical and psychosocial support. Researchers agree that assessment of QOL among HPN patients should be conducted with a therapy-specific instrument. ${ }^{1,2,39}$ Currently, only one validated instrument exists for use with HPN dependent adults; this questionnaire produces a composite score that can be used in research for comparison over time and between treatment groups. ${ }^{10,40}$

The HPN-PROQ may offer a more clinically relevant approach to identify and address lifestyle concerns when used with individual patients in a medical office or home care setting. 
We suggest that the HPN-PROQ be completed prior to an office or home care visit, in a similar way to a medical review of systems, at routine intervals or whenever there are important QOL issues to discuss. Rather than producing an overall composite QOL score, responses could be used to help patients prioritize important lifestyle issues they may wish to discuss with their clinician and provide an opportunity for more in-depth discussion as to why they are feeling the way they are feeling.

Validation of newly developed instruments is a rigorous process that includes the establishment of content validity. ${ }^{25}$ Government guidelines recommend the inclusion of substantial patient input in PRO development. ${ }^{22}$ Sample characteristics should reflect the patient population to be included in future studies or in clinical practice. ${ }^{41}$ Cognitive interviewing is a commonly employed evidence-based research method to improve content validity of newly developed instruments because it assesses whether common terms are understood by the target population. ${ }^{42}$ In this study, we used qualitative measures to establish content validity in a homogeneous group of adult HPN dependent adults. The demographic characteristics, diagnoses, length of HPN dependency, and parenteral nutrition infusion schedule compare favorably to similar studies ${ }^{20,31}$ and to a cohort of adult HPN patients enrolled in the Sustain registry. ${ }^{11}$ We identified item-specific issues with lack of clarity regarding word choice, comprehension, and ambiguity and uncovered unfavorable and potentially problematic items when HPN dependent adults evaluated the HPN-PROQ. For example, patients suggested using "central line" to replace "catheter" and "emptying an ostomy bag" instead of "changing the appliance". While clinicians understand these medical terms, more patient-friendly terminology was preferred.

Replacement of the Likert scale with the VAS response scale also makes the HPN-PROQ more "user-friendly" for both patients and clinicians. Use of VAS in the clinical setting with 
self-administered questionnaires is commonly used to evaluate pain, mood, and patient satisfaction, are advantageous in that they decrease ambiguity or response descriptors/options, and require less time to complete. ${ }^{43,44}$ The HPN-PROQ de-emphasizes the significance of an overall score and may turn attention to factors influencing QOL and lifestyle adaptation with HPN.

Clinician input is also extremely important in the development of a PRO questionnaire and their perception of the relevance of such a tool would likely influence its use. Five or more experts are required to have a valid sample for CVI. ${ }^{29}$ This study included 13 clinicians with expertise in HPN care and management. Given the multidisciplinary team management of HPN, we recruited physicians, nurses, registered dietitians, pharmacists, and home care advocates for participation. ${ }^{45}$ The I-CVI of the PRO items were analyzed using conservative criteria for retention with only items achieving a $\mathrm{K} \geq 0.783$ retained. HPN experts rated most of the items in the PRO as highly relevant, leading to an acceptable average S-CVI score of 0.96 , which is comparable to results from other content validation studies. ${ }^{32,33,38,41}$

Five items with a borderline acceptable I-CVI score of 0.77 were eliminated because of the previously established criterion of $\geq 0.783$. While this reduces the number of items on the questionnaire and potentially decreases participant burden, elimination of these items may leave out some important constructs of HPN related QOL. Two food-related items were eliminated including "eating cause me to have gas or feel bloated" and "eating causes me to have pain". It should be noted that these items represent physical aspects of eating and those that are psychosocial in nature including "I eat and enjoy the foods I want to eat" and "I can participate comfortably in social situations where food is served" were retained. Furthermore, the HPNPROQ is intended to cue the clinician to ask the patient to describe more specifically what they 
are struggling with so it is possible that a patient who is unable to eat and enjoy food would be prompted to explain why.

The results and methodology of this study are consistent with similar research using the CVI to establish content validity. For example, in the validation of the Osteoporosis Risk Assessment Tool, 8 experts were selected from among nationally known clinicians and researchers holding well-respected reputations in osteoporosis risk prevention and treatment. ${ }^{41}$ Fourteen designated experts completed the CVI to establish item relevance for a measure of patient-centered communication with more liberal CVI criteria $(>0.70)$ resulting in the removal of four items from the prototype questionnaire. ${ }^{32}$ Similarly, a sample of 9 experts participated in a content validity study to evaluate a muscle endurance questionnaire with an I-CVI criterion of $<0.78$ resulting in the deletion of 14 items. $^{33}$

PRO instruments enhance patient-clinician communication and inform plans of care to better target interventions that will improve patient outcomes. ${ }^{46,47}$ Evidence from randomized controlled trials suggests that the use of PROs in clinical practice is valuable in improving the discussion and detection of QOL constructs, but has less of an impact on how clinicians manage patient problems or on subsequent patient outcomes. ${ }^{48}$ Many of the reasons for this may lie in the ways in which PROs fit (or do not fit) into the routine ways in which patients and clinicians communicate with each other, how clinicians make decisions, and how healthcare is organized. Researchers recommend identifying ways in which PROs can be better incorporated into the routine care of patients by combining qualitative and quantitative methods. ${ }^{48}$

Regardless, use of PRO instruments can provide several advantages: to alert the clinician to the patient's concerns about their QOL, to clarify the patient's priorities for care, and to facilitate conversation between patients and clinicians about these issues. ${ }^{46}$ This is especially important as patients and physicians do not always agree on which outcomes of care are most 
important. ${ }^{47}$ For example, patients with multiple sclerosis are less concerned than their clinicians about physical disability in their illness and are more concerned with issues impacting their QOL. ${ }^{49}$ Studies have also shown that provision of PRO feedback to clinicians results in an increase use of health services and referrals, more timely reporting and management of symptoms, less patient anxiety, fewer preventable emergency room and office visits or calls, greater patient adherence to advice, greater satisfaction with care, more effective selfmanagement, and more efficient use of resources. ${ }^{50-52}$ As patients may be embarrassed or hesitant to initiate conversations with their clinicians around psychosocial issues, having the HPN-PRO may facilitate important patient-centered discussions.

The HPN-PROQ illustrates acceptable content validity as determined by HPN patients and expert home care clinicians. Future studies with psychometric testing should be conducted in a large sample of more diverse HPN patients to provide additional support for the conceptual framework of the HPN-PROQ and to determine its relevance with both short term/temporary HPN and long term/lifelong HPN dependency. It may also be important to compare results from the HPN-PROQ to the HPN-QOL ${ }^{\odot}$. Clinical utility should also be assessed to verify the impact of the HPN-PROQ on treatment decision-making. Specifically, future studies should include observations of patient-clinician interaction while using the HPN-PROQ with an assessment of communication and patient and clinician satisfaction. Additional research is necessary to determine the timing and frequency for which the HPN-PROQ should be administered.

\section{Limitations}

There are some limitations in content validity studies that should be noted. Feedback is subjective, and may introduce biases to the study, that may exist among the patients, experts, and researchers. Additionally, there was a demographic limitation among the HPN patients, which had a high rate of Caucasian females (72\%). However, there is no reason to suspect that this 
would impact the data in a way that would impair the clarity, relevance, and acceptability of the revised components of the HPN-PROQ. Selection bias is likely as participants were self-selected, interested, and willing to participate. Lastly, this study was conducted with adult HPN patients only and therefore, results cannot be generalized to pediatric patients or their parents or caregivers. The reliability testing of the use of this instrument should be undertaken when used with larger numbers of patients in practice.

\section{Conclusion}

To the best of our knowledge, this study adheres to standard procedures for content validation and these data provide evidence that the final version of the HPN-PROQ is a content valid questionnaire with relevant, clear, and understandable items and response scale. Cognitive interviewing, member checking, and calculation of the CVI were utilized to demonstrate the content validity of the HPN-PROQ. The methodology (i.e. interview scripts, iterative analysis, actions taken to delete or modify an item in response to CI, and member checking) is appropriate to assess content validity. These methods help provide a valid set of items which will in-turn increase the likelihood of reliable responses when used by HPN patients. Overall, most of the items included in the original HPN-PROQ were understood by HPN patients and interpreted as intended by the researchers. The questions were described as "clear" and "easy to answer" and represented important areas in the lives of HPN patients.

Although the primary intent of the cognitive interviews was to evaluate if HPN patients in our sample understood the items and could offer congruent interpretations, we also confirmed the desire by HPN patients to use the HPN-PROQ. Study participants frequently expressed their gratitude for the project and were eager to participate; repeatedly commenting on the relevance of the issues raised in the HPN-PROQ and that effective communication with their clinicians about these issues is meaningful to them. This study found that patients perceived the need for 
an instrument such as the HPN-PROQ, which could be used to facilitate communication among HPN patients and their clinicians to assist in the improvement of patient-care. 


\section{References}

1. Winkler MF. Quality of life in adult home parenteral nutrition patients. JPEN J Parenter Enteral Nutr. 2005;29:162-170.

2. Baxter JP, Fayers PM, McKinlay AW. A review of the quality of life of adult patients treated with long-term parenteral nutrition. Clin Nutr. 2006;25:543-553.

3. Silver HJ. The lived experience of home total parenteral nutrition: an online qualitative inquiry with adults, children, and mothers. Nutr Clin Pract. 2004;19:297-304.

4. Persoon A, Huisman-de Waal G, Naber TA, et al. Impact of long-term HPN on daily life in adults. Clin Nutr. 2005;24:304-313.

5. Roskott AM, Huisman-de Waal G, Wanten GJ, et al. Screening for psychosocial distress in patients with long-term home parenteral nutrition. Clin Nutr. 2013;32:396-403.

6. Aeberhard C, Leuenberger M, Joray M, Ballmer PE, Muhlebach S, Stanga Z. Management of home parenteral nutrition: a prospective multicenter observational study. Ann Nutr Metab. 2015;67:210-217.

7. Winkler MF, Smith CE. Clinical, social, and economic impacts of home parenteral nutrition dependence in short bowel syndrome. JPEN J Parenter Enteral Nutr. 2014;38:32S-37S.

8. Huisman-de Waal G, Schoonhoven L, Jansen J, Wanten G, van Achterberg T. The impact of home parenteral nutrition on daily life: a review. Clin Nutr. 2007;26:275-288.

9. Winkler MF, Ross VM, Piamjariyakul U, Gajewski B, and Smith CE. Technology dependency in home care: Impact on patients and their family caregivers. Nutr Clin Pract. 2006;21:544-556.

10. Baxter JP, Fayers PM, McKinlay AW. The clinical and psychometric validation of a questionnaire to assess the quality of life of adult patients treated with long-term parenteral nutrition. JPEN J Parenter Enteral Nutr. 2009;34:131-142.

11. Winkler MF, DiMaria-Ghalili RA, Guenter P, et al. Characteristics of a cohort of home parenteral nutrition patients at the time of enrollment in the Sustain Registry. JPEN J Parenter Enteral Nutr. 2016;40:1140-1149.

12. Berghöfer P, Fragkos K, Baxter J, et al. Development and validation of the disease-specific Short Bowel Syndrome-Quality of Life (SBS-QoL ${ }^{\text {TM}}$ ) scale. Clin Nutr. 2013;32:789-796.

13. Jeppesen P, Pertkiewicz M, Forbes A, et al. Quality of life in patients with short bowel syndrome treated with the new glucagon-like peptide- 2 analogue teduglutide-analyses from a randomised, placebo-controlled study. Clin Nutr. 2013;32(5):713-721.

14. Pironi L, Baxter JP, Lauro A, et al. Assessment of quality of life on home parenteral nutrition and after intestinal transplantation using treatment-specific questionnaires. Am J Transplant. 2012;Supp14:S60-S66. 
15. Theilla M, Kagan I, Chernov K. Cohen J, Kagan I, Singer P. Self-evaluation of quality of life among patients receiving home parenteral nutrition: A validation study. JPEN J Parenter Enteral Nutr. Published Online: April 25, 2017 (doi.org/10.1177/0148607117704812).

16. Winkler MF, Smith CE. The impact of long-term home parenteral nutrition on the patient and the family: achieving normalcy in life. J Infus Nurs. 2015;38:290-300.

17. Snyder CF, Jensen R, Courtin SO, Wu AW. PatientViewpoint: a website for patient-reported outcomes assessment. Qual Life Res. 2009;18:793-800.

18. Lohr KN, Zebrack BJ. Using patient-reproted outcomes in clinical practice: challenges and opportunities. Qual Life Res. 2009;18:99-107.

19. Greenhalgh J. The applications of PROs in clinical practice: what are they, do they work, and why? Qual Life Res. 2009;18:115-123.

20. Winkler MF, Hagan E, Wetle T, Smith C, Maillet JO, Touger-Decker R. An exploration of quality of life and the experience of living with home parenteral nutrition. JPEN J Parenter Enteral Nutr. 2010;34:395-407.

21. Winkler MF, Wetle T, Smith C, Hagan E, Maillet J, Touger-Decker R. The meaning of food and eating among home parenteral nutrition dependent adults with intestinal failure: a qualitative inquiry. J Amer Diet Assoc. 2010;110:1676-1683.

22. Department of Health and Human Services. Food and Drug Administration. Guidance for industry: patient-reported outcome measures: use in medical product development to support labeling claims: draft guidance. 2009. https://www.fda.gov/downloads/drugs/guidances/ucm193282.pdf. Accessed January, 212017.

23. Payne SLB. The Art of Asking Questions: Studies in Public Opinion, 3. Princeton: Princeton University Press; 2014.

24. Jabine TB, Council NR. Cognitive aspects of survey methodology: building a bridge between disciplines: report of the advanced research seminar on cognitive aspects of survey methodology. Washington, DC:National Academy Press, 1984.

25. Patrick DL, Burke LB, Gwaltney CJ, et al. Content validity-establishing and reporting the evidence in newly developed patient-reported outcomes (PRO) instruments for medical product evaluation: ISPOR PRO good research practices task force report: part 2 - assessing respondent understanding. Value in Health. 2011;14:978-988.

26. Willis GB. Cognitive interviewing: A tool for improving questionnaire design. Washington DC: Sage Publications, 2004.

27. Willis GB. Analysis of the cognitive interview in questionnaire design: understanding qualitative research. New York, NY: Oxford University Press, 2015. 
28. Wynd CA, Schmidt B, Schaefer MA. Two quantitative approaches for estimating content validity. West J Nurs Res. 2003;25:508-518.

29. Polit DF, Beck CT. The content validity index: are you sure you know what's being reported? critique and recommendations. Res Nurs Health. 2006;29:489-497.

30. Lynn MR. Determination and quantification of content validity. Nurs Res. 1986;35:382-385.

31. Chopy K, Winkler M, Schwartz-Barcott D, Melanson K, Greene G. A qualitative study of the perceived value of membership in The Oley Foundation by home parenteral and enteral nutrition consumers. JPEN J Parenter Enteral Nutr. 2015;39:426-433.

32. Zamanzadeh V, Ghahramanian A, Rassouli M, Abbaszadeh A, Alavi-Majd H, Nikanfar AR. Design and implementation content validity study: development of an instrument for measuring patient-centered communication. J Caring Sci. 2015;4:165-178.

33. Larsson H, Tegern M, Monnier A, et al. Content validity index and intra- and inter-rater reliability of a new muscle strength/endurance test battery for Swedish soldiers. PLos One. 2015; 10(7) e0132185.

34. Braun V, Clarke V. Using thematic analysis in psychology. Qual Res Psychol. 2006;3:77101.

35. Doyle S. Member checking with older women: a framework for negotiating meaning. Health Care Women Int. 2007;28:888-908.

36. Birt L, Scott S, Cavers D, Campbell C, Walter F. Member checking: a tool to enhance trustworthiness or merely a nod to validation? Qual Health Res. 2016;26:1802-1811.

37. Krefting L. Rigor in qualitative research: the assessment of trustworthiness. Am J Occup Ther. 1991;45:214-222.

38. Cicchetti DV, Sparrow SA. Developing criteria for establishing interrater reliability of specific items: applications to assessment of adaptive behavior. Am J Ment Defic. 1981;86:127-137.

39. Chambers A, Powell-Tuck J. Determinants of quality of life in home parenteral nutrition. Curr Opin Clin Nutr Metab Care. 2007;10:318-323.

40. Baxter JP, Fayers PM, McKinlay AW. The development and translation of a treatmentspecific quality of life questionnaire for adult patients on home parenteral nutrition. Eur E J Clin Nutr Metab. 2008;3:e22-e28.

41. Wynd CA, Schaefer MA. The osteoporosis risk assessment tool: establishing content validity through a panel of experts. Appl Nurs Res. 2002;15:184-188. 
42. Willis GB, Artino AR. What do our respondents think we're asking? Using cognitive interviewing to improve medical education surveys. J Grad Med Educ. 2013;5:353-356.

43. Couper MP, Tourangeau R, Conrad FG, Singer E. Evaluating the effectiveness of visual analog scales. Soc Sci Comput Rev. 2006;24:227-245.

44. Voutilainen A, Pitkaaho T, Kvist T, Vehvilainen-Julkunen K. How to ask about patient satisfaction? The visual analogue scale is less vulnerable to confounding factors and ceiling effect than a symmetric Likert scale. J Adv Nurs. 2016;72:946-957.

45. Guenter P, Winkler M. Long-term home parenteral nutrition: it takes an interdisciplinary approach. J Infus Nurs. 2014;37:389-395.

46. Espallargues M, Valderas, Alonso J. Provision of feedback on perceived health status to health care professionals: a systematic review of its impact. Med Care. 2000;38:175-186.

47. Marshall S, Haywood K, Fitzpatrick R. Impact of patient-reported outcome measures on routine practice: a structured review. J Eval Clin Pract. 2006;12:559-568.

48. Greenhalgh J, Long A, Flynn R. The use of patient reported outcome measures in routine clinical practice: lack of impact or lack of theory? Soc Sci Med. 2005;60:833-843.

49. Rothwell PM, McDowell Z, Wong CK, Dorman PJ. Doctors and patients don't agree: cross sectional study of patients' and doctors' perceptions and assessments of disability in multiple sclerosis. BMJ. 1997;314:1580-1583.

50. Fung CH, Hays RD. Prospects and challenges in using patient-reported outcomes in clinical practice. Qual Life Res. 2008;17:1297-1302.

51. Donaldson MS. Taking PROs and patient-centered care seriously: incremental and disruptive ideas for incorporating PROs in oncology practice. Qual Life Res. 2008;17:1323-1330.

52. Dawson J, Doll H, Fitzpatrick R, Jenkinson C, Carr AJ. The routine use of patient reported outcome measures in healthcare settings. BMJ. 2010;340:c186. 
Table 1. Demographic Characteristics of Home Parenteral Nutrition Patients ( $\mathrm{n}=32)$

Characteristic

Age (years)

Sex

Male

Female

Race

Caucasian

Indian

Highest Level of Education

High School Diploma

Associate Degree

Bachelor Degree

Master Degree

Doctoral Degree

\section{Results}

$52 \pm 15$

$9(28 \%)$

$23(72 \%)$

$31(97 \%)$

$1(3 \%)$

$15(47 \%)$

$2(6 \%)$

$7(22 \%)$

$6(19 \%)$

$2(6 \%)$

Medical Diagnosis and Reason for Home Parenteral Nutrition

Short Bowel Syndrome

Gastroparesis

Pseudo Obstruction

Other

Length of HPN Dependency (years)

Parenteral Nutrition Infusions per week

Parenteral Nutrition Infusion (hours)
$22(69 \%)$

$3(9 \%)$

$4(13 \%)$

$3(9 \%)$

$12 \pm 10 \quad(1-34)$

$6.5 \pm 1.1 \quad(6-7)$

$12 \pm 4 \quad(11-16)$ 
Table 2. Patient Reported Outcome (PRO) Item-Content Validity Index (I-CVI) Rating by Expert Clinicians $(\mathrm{n}=13)$

\begin{tabular}{|c|c|c|}
\hline Item \# - PRO & $\begin{array}{c}\text { Number of } \\
\text { Experts Rating } \\
\text { PRO } \\
\text { as "3" or "4" }\end{array}$ & $\mathbf{K}^{*}$ \\
\hline \multicolumn{3}{|l|}{$\begin{array}{l}\text { Section } 1 . \text { During the past } 2 \text { weeks, please estimate how often } \\
\text { you experienced any of the following situations. }\end{array}$} \\
\hline 1. I felt like my health limited the things I want to do in my life. & 13 & 1.00 \\
\hline 2. $\quad$ Being on TPN was difficult to cope with emotionally. & 13 & 1.00 \\
\hline $\begin{array}{l}\text { 3. My daily activities were limited by my TPN infusion } \\
\text { schedule. }\end{array}$ & 11 & 0.85 \\
\hline 4. $\quad$ Carrying my TPN solution limited what I could do. & 10 & 0.77 \\
\hline 5. I felt physically strong. & 10 & 0.77 \\
\hline 6. I was able to participate in the activities I enjoy. & 12 & 0.92 \\
\hline 7. I was able to walk without difficulty. & 11 & 0.85 \\
\hline 8. I was able to climb up and down stairs without difficulty & 9 & 0.69 \\
\hline 9. I was able to rise from a chair or bed without difficulty. & 12 & 0.92 \\
\hline $\begin{array}{l}\text { 10. I was able to pick up an object from the floor without } \\
\text { difficulty. }\end{array}$ & 8 & 0.62 \\
\hline 11. I needed to nap when I felt tired. & 7 & 0.54 \\
\hline 12. I had enough strength and stamina to do daily chores or work. & 12 & 0.92 \\
\hline 13. The TPN pump disrupted my sleep. & 13 & 1.00 \\
\hline $\begin{array}{l}\text { 14. My sleep was disrupted because I had to get up to move my } \\
\text { bowels or empty my ostomy bag. }\end{array}$ & 12 & 0.92 \\
\hline 15. My sleep was disrupted because I had to get up to urinate. & 13 & 1.00 \\
\hline 16. I ate comfortably in social situations and around others. & 12 & 0.92 \\
\hline 17. Eating caused me to have gas or feel bloated. & 10 & 0.77 \\
\hline 18. Eating caused me to have pain. & 10 & 0.77 \\
\hline 19. I had episodes of uncontrollable diarrhea. & 12 & 0.92 \\
\hline 20. I had to move my bowels shortly after I ate food. & 10 & 0.77 \\
\hline $\begin{array}{l}\text { 21. I had to rearrange my daily plans because of how much } \\
\text { diarrhea I had. }\end{array}$ & 12 & 0.92 \\
\hline 22. I had episodes of uncontrollable ostomy leakage. & 13 & 1.00 \\
\hline 23. I had to empty my ostomy bag shortly after I ate food. & 9 & 0.69 \\
\hline $\begin{array}{l}\text { 24. I had to rearrange my daily plans because of how much } \\
\text { ostomy output I had. }\end{array}$ & 13 & 1.00 \\
\hline
\end{tabular}




\begin{tabular}{|c|c|c|}
\hline \multicolumn{3}{|l|}{$\begin{array}{l}\text { Section 2. How TRUE or FALSE are the following statements to } \\
\text { you? }\end{array}$} \\
\hline $\begin{array}{l}\text { 1. Good quality of life means being able to do what I want to do } \\
\text { when I want to do it. }\end{array}$ & 11 & 0.85 \\
\hline 2. I eat and enjoy the foods I want to eat. & 11 & 0.85 \\
\hline $\begin{array}{l}\text { 3. I am confident in my ability to perform TPN procedures on } \\
\text { my own. }\end{array}$ & 13 & 1.00 \\
\hline $\begin{array}{l}\text { 4. Having one or more nights or days without TPN is important } \\
\text { to me. }\end{array}$ & 13 & 1.00 \\
\hline 5. Having a shorter TPN infusion schedule is important to me. & 13 & 1.00 \\
\hline $\begin{array}{l}\text { 6. I feel relieved knowing my nutritional needs are being met by } \\
\text { TPN therapy. }\end{array}$ & 13 & 1.00 \\
\hline $\begin{array}{l}\text { 7. I am fearful of developing complications related to my TPN } \\
\text { therapy and/or central line. }\end{array}$ & 12 & 0.92 \\
\hline 8. I understand my need for being on TPN therapy. & 13 & 1.00 \\
\hline $\begin{array}{l}\text { 9. I know and have been trained on how to manage my TPN } \\
\text { therapy. }\end{array}$ & 13 & 1.00 \\
\hline $\begin{array}{l}\text { 10. I know and have been trained on how to care for my central } \\
\text { line. }\end{array}$ & 13 & 1.00 \\
\hline 11. I know and have been trained on how to use my pump. & 13 & 1.00 \\
\hline $\begin{array}{l}\text { 12. I know and have been trained on the signs and symptoms of a } \\
\text { central line infection. }\end{array}$ & 13 & 1.00 \\
\hline $\begin{array}{l}\text { 13. I know and have been trained on signs and symptoms of } \\
\text { dehydration. }\end{array}$ & 13 & 1.00 \\
\hline $\begin{array}{l}\text { 14. I know and have been trained about my diet and what I should } \\
\text { be eating. }\end{array}$ & 13 & 1.00 \\
\hline $\begin{array}{l}\text { 15. I know whom to call when I have questions about my TPN } \\
\text { therapy. }\end{array}$ & 13 & 1.00 \\
\hline 16. I feel emotionally supported by my family and friends. & 12 & 0.92 \\
\hline 17. I feel well supported by my home care specialists. & 13 & 1.00 \\
\hline $\begin{array}{l}\text { 18. I received information about local or national support groups } \\
\text { for TPN therapy. }\end{array}$ & 13 & 1.00 \\
\hline 19. I wish I knew more about my TPN therapy. & 12 & 0.92 \\
\hline
\end{tabular}

I-CVI, Item-level content validity index; K, kappa; PRO, Patient Reported Outcome; TPN total parenteral nutrition

*K computed using the formula $\left.\mathrm{K}=\left(\mathrm{I}-\mathrm{CVI}-\mathrm{P}_{\mathrm{c}}\right) / 1-\mathrm{P}_{\mathrm{c}}\right)$ where $\mathrm{Pc}=$ probability of a chance occurrence. Items were retained with $\mathrm{K} \geq 0.783$. Interpretation criteria for $\mathrm{K}$ based on: Polit $\mathrm{DF}$, Beck CT. The content validity index: are you sure you know what's being reported? critique and recommendations. Res Nurs Health. 2006;29:489-497. 